\title{
Comunicação e tempo: reflexões em favor das diferenças
}

\author{
Márcio Souza Gonçalves' \\ https://orcid.org/0000-0002-8994-6745 \\ Paulo Bernardo Ferreira Vaz" \\ https://orcid.org/0000-0001-9868-4081 \\ I - UERJ \\ Rio de Janeiro (RJ), Brasil \\ II - UFMG \\ Belo Horizonte (MG), Brasil
}

Resumo: Discute-se, no presente texto, a articulação entre tempo e comunicação. Em uma primeira parte, são desenhados dois paradigmas de compreensão da relação entre comunicação e tempo: um paradigma dito epocalista, que será fortemente criticado, e um paradigma alternativo, que opera de modo não-linear e mais atento às diferenças existentes. Na segunda parte, pensa-se a questão da diferença na contemporaneidade brasileira.

Palavras-chave: comunicação; tempo; diferença; atualidade; Brasil.

Abstract: Communication and time: thoughts in favor of differences - The paper discusses the relationship between time and communication. First of all, two possible paradigms of comprehension of this relationship are indicated: the first one, which is called epochalist, will be strongly criticized; the second one, which emphasizes differences, operates in a non-linear mode and is more akin to the perspective defended by the paper. After that, the problem of difference in Brazilian contemporaneity is analyzed.

Keywords: communication; time; difference; contemporaneity; Brazil.

\section{Introdução}

O presente texto se divide em duas partes.

Na primeira, é desenhado um modo de articular comunicação e tempo; na segunda, a questão da diferença é acrescentada a esses dois primeiros termos, em uma discussão especialmente oportuna para os dias que correm. 
Inicialmente, é delineado um paradigma para a compreensão da articulação entre comunicação e tempo denominado epocalismo, ao qual será contraposto outro que não se baseia na ideia de épocas em sucessão. Este segundo paradigma é aqui considerado como mais adequado a articular de um modo sutil as semelhanças e diferenças que compõem qualquer contexto histórico.

Na segunda parte, encontra-se uma reflexão sobre a contemporaneidade e sua complexidade baseada no paradigma não epocalista desenhado anteriormente. Trata-se, então, de refletir sobre nosso tempo considerando-o não definível a partir de categorias gerais, o que se tornará claro no andamento do texto.

Tais reflexões, relativamente autorais, refletem o andamento das pesquisas dos dois autores e procuram contribuir, na medida do possível, para uma reflexão ao mesmo tempo abstrata e eticamente engajada acerca do tempo em geral e de nossa atualidade em particular.

\section{Tempo, comunicação, semelhança e diferença: contra o epocalismo}

A seguir será desenhada uma maneira de articular comunicação e tempo da qual nos distanciamos, maneira que nomeamos alhures epocalismo (GONÇALVES; CLAIR, 2014). A esse desenho do epocalismo segue sua crítica e nossa proposta de um modo alternativo para compreender a relação entre os dois termos. Dada a limitação de tamanho do presente texto, seguiremos de modo relativamente esquemático e sem desenvolver longamente a argumentação.

Um modo bastante corrente para se pensar a temporalidade no campo da comunicação é o que trabalha opondo modernidade e pós-modernidade (cf., por exemplo, o conjunto da obra de Michel Maffesoli). Trata-se da forma mais comum do que entendemos por epocalismo. A modernidade seria definida por uma série de elementos, tais como racionalidade, binarismo, consciência, centralidade, ordem, transparência, individualismo; a pós-modernidade, por seu turno, explodiria as categorias modernas notadamente privilegiando seus inversos, como a emoção e a afetividade, o fim das oposições binárias em favor de um pluralismo do múltiplo, as hibridizações e perdas de limite da consciência, a ausência de centro, uma desordem criativa, a opacidade de corpos irredutíveis à luz límpida da razão, o ciborgue. Da modernidade das luzes teríamos passado à pós-modernidade dos fluxos de signos, mercadorias, máquinas, corpos etc, que marcam sobretudo as grandes metrópoles de nosso tempo recente.

A rigor, para que o esquema lógico explicativo fique completo, deve ser acrescentado um termo, a pré-modernidade, anterior à configuração moderna, sendo o pré-moderno marcado genericamente por uma forma de coletivismo ou holismo, totalmente não individualista, onde a razão ainda não se constituiu como elemento organizador da subjetividade humana. O paradigma completo compreende então, em sucessão lógica e cronológica, pré-modernidade, modernidade e pós-modernidade. 
A terminologia para designar cada uma dessas épocas e, do mesmo modo, sua localização temporal podem variar, mas o paradigma, a despeito dessas variações semânticas, permanece intocado. Assim, McLuhan, por exemplo, opõe a Galáxia de Gutenberg à Aldeia Global, por um lado, e às sociedades tribais primitivas, por outro (MCLUHAN, 1977, 2005). Ong, por sua vez, opõe a mente oral à "mente letrada" (ONG, 1998, p. 93). A passagem de uma época a outra, para o que interessa ao campo da comunicação, seria devida a alterações tecnológicas comunicacionais (invenção da escrita, do alfabeto, da prensa, das tecnologias elétricas e eletrônicas de comunicação, das mais recentes tecnologias digitais).

De modo geral, e a despeito das variações terminológicas, assim, o paradigma epocalista trabalha com uma sucessão de épocas distintas sendo a passagem de uma para outra operada por mutações, vistas como revolucionárias, em tecnologias de comunicação.

Uma primeira observação importante: cada época engloba, ao mesmo tempo, tanto uma dimensão cultural e social ampla, quanto uma dimensão individual. Assim, teríamos, por um lado, uma sociedade e uma cultura modernas e, por outro, uma subjetividade moderna; do mesmo modo, uma sociedade e uma cultura pós-modernas e uma subjetividade igualmente pós-moderna. O ciborgue seria a face subjetiva de nossa época pós-industrial.

Segunda observação importante: usualmente, nesse esquema de explicação, as tecnologias de comunicação ganham um grande peso, configurando algo que se pode chamar de determinismo tecnológico. Por determinismo tecnológico compreende-se aqui a tese de que a ação da tecnologia comunicacional é por si só de tal modo pregnante que seus efeitos independem das condições contingentes de uso a que são submetidas e dos contextos culturais em que agem. A tese mcluhaniana de que o meio é a mensagem (MCLUHAN, 2005) serve como um bom exemplo.

O esquema epocalista de pensar o tempo se baseia em dois pressupostos, em geral nunca explicitados, que exploraremos a seguir.

O primeiro nomeamos homogeneidade interna (para um desenvolvimento mais detalhado dessa argumentação, ver GONÇALVES , 2018), e assevera que cada época é internamente homogênea. Isso significa, concretamente, que os termos que a definem (ver acima os termos para as épocas pré-moderna, moderna e pós-moderna que alinhavamos) valem para o conjunto ou para a grande maioria de seus elementos. Assim, por exemplo, o racionalismo definiria o modo de existência da grande maioria das pessoas na modernidade, as derivas afetivas pós-modernas seriam então muito minoritárias ou inexistentes. Tal pressuposto é a primeira condição para que a nomeação de uma época tenha sentido: ela precisa ser idêntica a si mesma, precisa ser de tal modo homogênea e semelhante internamente que possa ter sentido como época individualizada. Se uma época qualquer é internamente heterogênea, se comporta muitas contradições internas, termina por se confundir com a que a antecede ou sucede, o que nos leva ao segundo pressuposto. 
Este pode ser nomeado como pressuposto da diferença externa. Trata-se da suposição de que toda época se distingue, globalmente, de época que a antecede e da que a sucede. Obviamente, o pressuposto da diferença externa depende da homogeneidade interna, dado que sem que se defina a identidade de uma dada época (homogeneidade interna) é impossível torná-la diferente do que quer que seja (diferença externa).

No paradigma epocalista esses dois pressupostos funcionam em conjunto: na medida em que existe, por exemplo, uma modernidade cujos elementos são homogêneos segundo um conjunto de parâmetros qualquer (racionalidade, individualismo etc), o que remete para o primeiro pressuposto, na medida em que existe, além disso, uma pós-modernidade cujos elementos são homogêneos segundo seus próprios parâmetros, podemos distinguir uma da outra e ordená-las tanto lógica, quanto cronologicamente. Prova pelo contrário da articulação dos dois pressupostos: se não se pode definir a identidade de cada época a partir de uma característica geral qualquer, não se pode operar uma distinção entre diferentes épocas.

Assim, em síntese, pode-se dizer que o epocalismo, ou seja, o modo de compreender a história das culturas e humanos como uma sucessão de épocas distintas, cada uma definida por determinadas características hegemônicas e dominantes, tem tanto uma dimensão subjetiva (a subjetividade das pessoas de uma época), quanto cultural (a cultura, termo aqui tomado em sentido bastante amplo, de uma época), e depende da ideia de que cada época é internamente homogênea (seus elementos são semelhantes a partir de um traço geral qualquer) e externamente diferente das outras épocas (diferença externa).

Não vamos detalhar aqui, por uma questão de espaço, a presença do paradigma epocalista no campo da comunicação. Indicamos apenas que essa presença tem uma longa trajetória e - com grandes variações semânticas no modo de nomear as épocas definidas e diferenças no modo de recortar os momentos cronológicos de passagem de uma época a outra - tem sido constante em autores de matizes os mais variados.

\section{Limites do epocalismo}

Sumariamente, o problema básico do epocalismo é que, para subsumir a imensa quantidade de elementos distintos que compõem um contexto cultural qualquer em um dado período de tempo sob uma etiqueta ampla, é necessário operar com categorias analíticas extremamente gerais. Ora, o ponto é que tais categorias gerais e genéricas são fracas do ponto de vista da análise e de uma efetiva descrição e compreensão da realidade.

Se se olha de muito perto, todo contexto histórico exibe uma proliferação de heterogeneidades diferenciais que impossibilita a utilização de categorias gerais; a solução epocalista é então olhar de bastante longe (mais adiante defenderemos a utilização de uma distância média), de modo que as diferenças se esbatam em favor de uma semelhança global; com isso cria-se uma curiosa forma de cegueira. 
Assim, seguindo com o exemplo do qual nos servimos acima, a modernidade e a correlata subjetividade moderna se definiriam, entre outras coisas, pela racionalidade. Tem-se, então, a categoria geral racionalidade como traço distintivo da modernidade. O problema é que uma investigação das condições sociais de existência, por exemplo, na revolução industrial, ou do modo de viver e pensar de pessoas ao longo do século XIX, indica claramente que, mesmo havendo uma dimensão de razão presente, de modo algum ela tem poder de definir a vida e a mentalidade dos humanos em questão. A racionalidade coexiste com enormes doses de irracionalidade, afetividade, paixão, loucura. Veja-se, quanto a esse ponto, a vida e a mentalidade dos mineiros no magnífico Germinal de Émile Zola (1979). Nada mais distante da transparência da razão supostamente moderna. O universo dos que trabalham nas minas, mesmo quando estão na superfície, é o de relações sociais violentas e agressivas, o de um sexo solto e muito distante da territorialização conjugal burguesa, o de uma proximidade física em ambientes onde a racionalidade participa muito pouco da organização do espaço da casa. Mesmo a identidade sexual se esbate na escuridão da mina (Etienne tomava Catherine por um rapaz). O desregramento do mundo mineiro põe em xeque ao longo de todo o livro a ordem luminosa da gestão racional.

O traço geral racionalidade do epocalismo falha então em permitir um entendimento adequado do contexto histórico designado pelo termo modernidade na exata medida em que desqualifica uma série enorme de elementos não-racionais como se não existissem ou não tivessem importância, desqualificação feita para salvar a razão como etiqueta mor. A oposição entre modernidade racional e pré-modernidade mítica ou pós-modernidade (o raciocínio é o mesmo) precisa varrer para baixo do tapete as enormes doses de irracionalidade moderna e a racionalidade mítica ou pós-moderna. Tenha-se em mente, quanto a essa razão pré-moderna, por exemplo, que Lévi-Strauss falou em uma ciência neolítica (LÉVI-STRAUSS, 2010) e Viveiros de Castro em metafísicas canibais (VIVEIROS DE CASTRO, 2015), cada um apontando, a seu modo, para essa racionalidade não moderna.

\section{Se não o epocalismo, então o quê?}

Desenha-se aqui uma maneira, bastante distinta do epocalismo, de articular comunicação e tempo. Os pressupostos envolvidos e os escopos de análise são outros.

Em primeiro lugar, trata-se de romper com o pressuposto da homogeneidade interna, sustentando que todo contexto histórico comporta elementos heterogêneos e mesmo contraditórios não sendo analiticamente viável e produtiva sua subsunção sob um traço único. De modo mais simples, pode-se dizer que todo contexto histórico é rico em diferenças e que não há uma suposta massa homogênea. Assim, um exemplo, tomando a escrita como traço distintivo: não há sentido em falar em cultura escrita idealizando uma espécie de onipresença do letramento, pois deve-se considerar que dentro das culturas ditas escritas há uma enorme massa de comunicação oral, muito maior mesmo do que 
a escrita, massa oral que relativiza a força da escrita e seus supostos poderes (por exemplo, os supostos poderes racionalizantes da escrita). Além disso, cada grupo que comporta escrita teria suas especificidades no modo de utilizá-la, relacioná-la com oralidade etc, de modo que falar em cultura escrita no singular seria uma grosseria teórica. Um autor especialmente sensível a essas complexidades é McKenzie, por exemplo, quando trata o modo "como na Inglaterra moderna oral, manuscrito e impresso se imbricam formando um universo irredutível a qualquer um dos três tomado isoladamente" (MCKENZIE, 2002, capítulo 9). No Brasil, destacamos as pesquisas de Marialva Barbosa, que assim se refere às misturas que têm lugar no campo da comunicação: "as misturas existem porque há sempre permanências do mundo anterior nos modos mais modernos, mas também porque modos de comunicação mais antigos permanecem em circulação dividindo espaço com as novas práticas durante várias décadas (às vezes, séculos)" (BARBOSA, 2013, p. 116) e que produziu um fundamental trabalho sobre a comunicação no universo dos escravos (BARBOSA, 2016).Isto posto, em suma, o uso de uma etiqueta genérica necessariamente não diz muito sobre os contextos existentes.

Em segundo lugar, em ligação com o rompimento com o pressuposto da homogeneidade interna, trata-se de abandonar o pressuposto da diferença externa. Se não há uma unidade chamada cultura escrita, não há sentido em opô-la a uma unidade também inexistente chamada cultura oral, idealizando uma história em que um suposto tipo de cultura teria sido substituído por outro, operando-se uma partilha binária entre tipos culturais (VIVEIROS DE CASTRO, 2015).

A oposição epocalista entre cultura oral e cultura escrita supõe equivocadamente uma unidade das culturas com escrita, de um lado, e das sem escrita ou orais, de outro, unidade que não existe na realidade, se se considera as imensas diferenças que separam diferentes grupos orais entre si e, do mesmo modo, grupos escritos entre si. Não existe um modo de existir cultural único chamado cultura oral que uniria em uma identidade reconhecível as culturas orais, o mesmo valendo para a escrita. Não há cultura oral, mas culturas orais, não há cultura escrita, mas culturas com escrita, o que esvazia a possibilidade de uma oposição entre a cultura oral e a cultura escrita. Além disso, um dado contexto com escrita pode ser tão diferente de outro com escrita quanto de um sem as letras.

Assim, em síntese, cada grupo cultural é heterogêneo e contraditório (violando o princípio lógico da identidade), não pode ser descrito por grandes etiquetas genéricas e não há sentido em compreender o tempo como substituição de uma suposta identidade cultural por outra.

Não há a cultura oral, não há a cultura escrita, o tempo não é a passagem de um bloco cultural a outro; há múltiplas culturas orais, tão diferentes entre si quanto das culturas escritas, há múltiplas culturas escritas, tão diferentes entre si quanto das culturas orais, a história é o agenciamento, em diferentes contextos, de oralidade e escrita. 
Uma palavra sobre o problema da escala de observação: sendo a diferença sempre relativa, dado que situada em função de algum parâmetro (dois carros são semelhantes para o parâmetro meio de transporte; um carro verde e uma samambaia são semelhantes para o parâmetro cor, mas diferentes quando se pensa em termos de inanimado e animado etc), o que se indica acima é a necessidade, na consideração da relação entre tempo e comunicação, fora do epocalismo, da adoção de escalas mais finas para a teorização. Concretamente, isso significa que é analiticamente mais interessante trabalhar com escopos temporais e espaciais mais restritos: em vez dos vários séculos da Galáxia de Gutemberg na cultura ocidental (MCLUHAN, 1977), operar como Londres nos primórdios da era moderna, por exemplo. Não podemos desenvolver tal caso aqui por questões de espaço e remetemos os interessados à obra The Nature of the Book que o aborda magistralmente (JOHNS, 1998).

Algumas palavras sobre a questão da mudança histórica: esta não deve ser compreendida como a sucessão de uma época por outra, mas antes sempre como um rearranjo, local e contingente, dos elementos heterogêneos que compõem qualquer grupamento histórico, eventualmente, se for o caso, feito com a presença de elementos novos. Assim, não se deve opor cultura manuscrita (uma unidade inexistente) à cultura impressa (unidade inexistente), mas compreender como um arranjo entre diversos elementos, dentre os quais oralidade e manuscrito, no norte da Europa, por exemplo, foi substituído, contingentemente, por novos arranjos com a introdução da tecnologia de impressão, que coexistiu com os diversos elementos anteriormente presentes, oralidade e manuscrito dentre outros. Em lugar de uma sucessão de blocos homogêneos, um rearranjo de estratos heterogêneos com eventual acrescentamento de novos estratos.

\section{O caso dos objetos textuais}

Esboçamos agora, incompleta e sucintamente, para tornar palpável a complexidade das relações entre tempo e comunicação e a insuficiência das grandes oposições genéricas do epocalismo, o caso dos objetos textuais. Indo contra a tese de que é mais importante operar com contextos mais localizados, tentaremos aqui uma reflexão de conjunto, articulando elementos da história dos livros (BARBIER \& BERTHO LAVENIR, 2003; BARBIER, 2006; CAVALLO \& CHARTIER, 2001; LYONS, 2011; FINKELSTEIN \& MCCLEERY, 2006).

Há não uma linha única dividida em manuscrito e impresso, como em diversas teorias epocalistas, mas um entrecruzamento de diversas linhas que se reordenam com a passagem do tempo. As diversas linhas serão indicadas a seguir, sua trança sendo a temporalidade dos objetos textuais em relação com as culturas.

Primeira linha: tipo de matéria-prima, com uma amplitude temporal grande, desde a argila mesopotâmica até os componentes dos aparelhos digitais atuais, passando por papiro, pergaminho e outras matérias mais exóticas. 
Segunda linha: formato dos objetos, também longa e variada, dos tabletes mesopotâmicos, até os aparelhos digitais atuais, comportando contudo, classicamente, alguns formatos mais fortes (rolo, códice, formatos eletrônicos).

Terceira linha: tipos de escrita, longa, com escritas ideográficas, silábicas, alfabéticas; sua especificidade é a hegemonia, para o nosso lado do mundo, do alfabeto.

Quarta linha: modo de produção, manuscrito, impresso, eletrônico.

Quinta linha: o universo da circulação e consumo dos textos, que na realidade é uma linha dividida em infinitas microlinhas, com suas variadas escansões e alterações.

Poderíamos prosseguir ainda indicando várias outras linhas (armazenamento, ensino, valorização, conteúdos armazenados etc), mas o que até aqui foi apresentado deve ser suficiente para dar uma noção, ainda que vaga, da complexidade da temporalidade em questão. Não há uma linha mestra escandida pela invenção de Gutemberg; há diversas linhas se enroscando de modo complexo.

Uma observação importante: as alterações em cada uma dessas linhas não se dão simultaneamente e não obedecem aos mesmos ritmos. Por exemplo: uma alteração fundamental do modo de produção se dá com a invenção da prensa, mas essa alteração não anula a presença de outro modo de produção, o manuscrito, e se dá sobre várias permanências, a do alfabeto, a do formato códice, a dos conteúdos, a dos leitores. O tempo é a composição dessas mudanças e permanências sempre complexas e contingentes. Contra o epocalismo, não uma linha única claramente organizada, mas sim linhas múltiplas em um entrelaçamento imprevisível.

\section{Diversidades no uno e contemporaneidade}

Ao desfiarmos várias linhas - cordões ou fios de ligamento entre um ponto e outro -, linhas que compõem uma trança ou cabo que os reúne, queremos destacar suas diferenças, entre si. Essa trança é tanto mais complexa quanto for o número de linhas nela usadas. Em vez da linha única, temporal, à qual recorrem as teorias epocalistas, lembramos da existência de sua diversidade.

Tomemos, então, um dos exemplos mais emblemáticos em largo uso na atualidade: a diversidade das cores do arco-íris. O grande arco luminoso originário de fenômenos físicos e meteorológicos, facilmente visível a olho nu, concentra-se naquele conjunto de bandas coloridas em enorme semi-círculo "estampado" no céu, sem outro suporte senão as gotículas de água suspensas na atmosfera refratárias da luz solar. A despeito de toda sua diversidade, apesar de sua aparente imaterialidade e fugacidade, o arco-íris é uno, um uno que é em si múltiplo. Neste primeiro exemplo ilustrativo, ressaltam-se não apenas as seis ou sete cores que o espectro nos permite visualizar no céu, mas todas as suas nuances que muito se multiplicam na escala cromática se recorrermos ao uso de aparelhos óticos de precisão. Os matizes decorrentes dessas/nessas cores são formados ou desfeitos com 
a passagem do tempo. Tempo nos dois sentidos: o clima que permitiu a visualização do fenômeno da natureza no espaço; e o cronológico que o espectador dispende para assistir gradativamente à sua formação e desaparecimento no horizonte luminoso.

Transpondo a diversidade das cores do arco-íris na natureza para sua simbologia na cultura ocidental nestas últimas décadas deparamo-nos com a militância LGBTQI1, que adota e levanta a bandeira do arco-íris em defesa de seus direitos civis na sociedade contemporânea. Observando melhor o fenômeno social da afirmação e reafirmação da diversidade de gêneros, voltamos à analogia da trança e à bandeira do arco-íris, composta pela diversidade de cores, lábaro que se faz símbolo de luta apenas por elas próprias, as diferenças das minorias.

Em analogia aos sentimentos de estranhamento e ódio da sociedade em geral em relação às pessoas cujas características são marcadas por sua disparidade entre seus contemporâneos, vale lembrar a frase antológica de Stendhal colocada na boca de Julien Sorel em 1827 em "O Vermelho e o Negro". Diz o seminarista Julien, alvo de críticas por demonstrar características e comportamento bastante distintos de seus colegas em Bésançon: "Minha presunção felicitou-se tantas vezes por eu ser diferente dos outros jovens camponeses. Pois bem, vivi o bastante para ver que diferença engendra ódio" (STENDHAL, 2013, p. 133). Muitos anos depois outra fala redentora foi acrescentada à frase stendhaliana, remarcando a consequência da assunção da diferença pelos seus portadores - componentes das soit disant minorias - na sociedade hodierna: se a diferença gera ódio, ela é também condição de salvação. Não deixamos de acrescentar aqui a palavra de ordem panfletária pelo respeito às minorias: "E viva a diferença!".

\section{Oh quão dessemelhante!}

Ao considerar, portanto, as dessemelhanças e distinções que compõem um contexto cultural percebido em um certo período de tempo, chamamos a atenção para a complexidade e heterogeneidade cada vez maior dos fenômenos sócio-culturais contemporâneos. Vejamos alguns aspectos da cultura na contemporaneidade, que tentaremos reduzir a exemplos ao mesmo tempo simples e complexos. De uma maneira geral, nossa pressa em resolver nossos pequenos e grandes problemas na vida cotidiana leva-nos a simplificações no entendimento de qualquer fenômeno. Em uma situação com muitas variáveis, costumamos colocar tudo em espaços e recipientes que acolhem coisas e pessoas congêneres, na forma classificatória mais singela, às vezes no limite da ingenuidade.

O setor da moda, por exemplo, apesar de ser social e economicamente tão diversificado, e estratificado, costuma receber uma visão globalizante. Em um determinado

1 LGBTQI: Conjunto de simpatizantes ou de pessoas que se auto-definem como Lésbicas, Gays, Bissexuais, Transsexuais, Queer e Intersexuais, sob a bandeira do arco-íris em defesa do respeito e da integridade da diversidade de gêneros. 
mês do ano paira no silêncio do ar a frase não dita, mas ouvida por todos: a moda é calças skinny para homens. Passamos a observar, em seguida, top-models portando calças apertadas em anúncios das mais conceituadas revistas de moda no mundo, homens são fotografados em festas frequentadas exclusivamente pela elite da elite social, e rapazes das periferias do Rio de Janeiro, Salvador e Belo Horizonte são flagrados em festas nos bairros mais pobres vestindo as mesmas (?) calças justíssimas. Onde estão as diferenças das/nas calças skinny?

Fotos de modelos vestindo sofisticadas roupas com tecido floral podem ser vistas nas páginas de Vogue, Metropolitan e Bazaar, ao mesmo tempo em que roupas similares (mas diferentes) são expostas em apertadas "gaiolas"/bancas nos shoppings populares, vendidas a preços acessíveis para mulheres subassalariadas que não andam menos na moda do que as frequentadoras de shoppings do Leblon no Rio, Iguatemi na Bahia e Diamond em Belo Horizonte. Onde estão as diferenças dos florais no vestuário feminino?

Ao mesmo tempo em que os desenhos florais vestem mulheres pobres e da elite no seu cotidiano, aparecem silkados em camisetas masculinas de todos as grifes ofertadas no mercado de roupas a todos os preços. Bem desenhados e multi-coloridos florais estampando roupas de cama e banho em algodão egípcio de centenas de fios, assim como fofíssimas roupas de banho em algodão 100\%, compõem o cenário de apartamentos de alto luxo; mas roupas de cama e banho com estampas florais ao mesmo tempo decoram os quartos e banheiros de barracões nas favelas dos grandes centros urbanos brasileiros. Onde estão as diferenças do uso dos florais nos edredons, lençóis, fronhas e toalhas?

Calçados esportivos cujas características ergonômicas são dadas como imprescindíveis para bem andar, correr e fazer exercícios, são lançados sucessivamente por marcas internacionais a preços similares em Paris, Nova lorque, Rio de Janeiro, Salvador e Belo Horizonte. Belos e confortáveis tênis calçam quem se dispôs a desembolsar grande soma de dinheiro para comprá-los. Imitações de seu design são, em seguida, produzidas no polo calçadista de Nova Serrana, Minas Gerais, alternativa industrial e comercial que permite a aquisição de tênis modernos a preços acessíveis por jovens empregados, subempregados ou desempregados que frequentam academias instaladas em galpões de bairros periféricos de Belo Horizonte, Salvador e Rio, quase do mesmo modo como rapazes da elite social e econômica frequentam as mais bem equipadas e caras academias dos mesmos centros urbanos. Onde estão as diferenças nesses calçados esportivos?

Academias instaladas por todos as regiões de todos os centros urbanos do Brasil, oferecem aos ginastas uma aparelhagem mais sofisticada (em academias-top) ou menos (em academias-pop) para todos os tipos de exercícios físicos. Esses espaços de serviços têm sido, aqui e agora, considerados como imprescindíveis para a preparação física e performance de jovens e adultos de todas as etnias, gêneros e estratos sociais. São espaços de exercícios e também de interações, de trocas de receitas de suplementos alimentares na ajuda fisiológica para aumento de massa muscular, melhora no metabolismo e tudo 
mais que diga respeito a cuidados e exibições corporais. Onde estão as diferenças da performance corporal e social, do uso de aparelhos e, eventualmente, de medicamentos desses jovens e adultos?

Se considerássemos, então, que tudo que é de um mesmo tempo se parece, poderíamos colocar sob uma mesma e ampla etiqueta todos os rapazes vestindo calças skinny? Todos os usuários de roupas de vestir, cama e banho com estampas florais? Poderíamos juntar em uma mesma quadra todos os desportistas que calçam tênis grifados de marcas internacionais ou degrifados fabricados em Nova Serrana? Admirando sua performance física, poderíamos marcar com uma mesma etiqueta jovens e adultos malhados frequentadores de academias no mesmo espaço, generalizando o culto ao corpo e ao consumo de suplementos alimentares como comum a todos, assemelhando-os fisicamente? Ou dessemelhando-os?

Parece-nos mais percuciente, ao contrário, perceber a miríade de singularidades que pulula sob a semelhança, os desvios, usos, derivas, as linhas de fuga, uma microssociologia das diferenças que compõem nossa realidade social (CERTEAU, 1994; DELEUZE \& GUATTARI, 1976).

\section{Considerações finais}

Esboçamos acima, em primeiro lugar, e tomando claramente uma posição, dois paradigmas alternativos para relacionar tempo e comunicação, um paradigma dito epocalista, e um paradigma alternativo que não opera com a ideia de épocas em sucessão. O caso dos objetos textuais foi abordado como típico para a compreensão de temporalidades irredutíveis ao paradigma epocalista.

A seguir, recorremos a variados exemplos ilustrativos de objetos vistos na sociedade de consumo na atualidade, positivando a existência de diferenças sob a capa da homogeneidade social. Se nos fartamos na apresentação de fenômenos exemplares, utilizando amplamente pontos de interrogação, foi para marcar também o fato de que o que aqui se apresenta é um pensamento em processo e não a conclusão de um percurso.

Acreditamos que o que foi desenvolvido durante o texto sustenta de modo claro a aposta que aqui se fez, de uma reflexão abstrata e engajada sobre o tempo em geral e sobre nosso tempo em particular.

Márcio Souza Gonçalves é professor Associado da Faculdade de Comunicação Social da Universidade do Estado do Rio de Janeiro (FCS/UERJ), Pós-Doutor em Comunicação pela UFMG e Doutor e Mestre em Comunicação e Cultura pela Universidade Federal do Rio de Janeiro. Foi Coordenador 
do Programa de Pós-Graduação em Comunicação (PPGC) da FCS/UERJ. É bolsista Prociência UERJ/FAPERJ.

msg@uerj.br

Paulo Bernardo Ferreira Vaz é professor no Programa de Pós-Graduação em Comunicação da Universidade Federal de Minas Gerais, doutor em Comunicação e Educação pela Université de Paris XIII (1983) e pós-doutor pela Universidade do Minho (2010). Integrante do Grupo de Pesquisa Historicidades das Formas Comunicacionais [ex-press].

paulobvaz@gmail.com

\section{Referências}

BARBIER, F. \& BERTHO-LAVENIR, C. Histoire des médias: de Diderot à internet. Paris: Armand Colin, 2003.

BARBIER, F. Histoire du livre. Paris: Armand Colin, 2006.

BARBOSA, M. Escravos e o mundo da comunicação: oralidade, leitura e escrita no século XIX. Rio de Janeiro: Mauad X, 2016.

. História da Comunicação no Brasil. Petrópolis, RJ: Vozes, 2013.

CAVALLO, G. \& CHARTIER, R. (Orgs.). Histoire de la lecture dans le monde occidental. Paris: Seuil, 2001.

CERTEAU, M. de. A invenção do cotidiano: 1. As artes de fazer. Petrópolis: Vozes, 1994.

DELEUZE, G. \& GUATTARI, F. O Anti-Édipo: capitalismo e esquizofrenia. Rio de Janeiro: Imago, 1976.

FINKELSTEIN, D. \& MCCLEERY, A. An introduction to book history. New York and London: Routledge, 2006.

GONÇALVES, M. S. Comunicação, cultura e subjetividade: perspectivas de análise. Trabalho apresentado ao Grupo de Trabalho Comunicação e Cultura do XXVII Encontro Anual da Compós, Pontifícia Universidade Católica de Minas Gerais, Belo Horizonte - MG, 05 a 08 de junho de 2018. Disponível em www.compos.org.br .

GONÇALVES, M. S.; CLAIR, E. T. S. Meios na história, história nos meios: paradigmas para a reflexão sobre comunicação e cultura. TRÍADE: Revista de Comunicação, Cultura e Mídia, v. 2, p. 157-172, 2014.

JOHNS, A. The nature of the book: print and knowledge in the making. Chicago and London: The University of Chicago Press, 1998.

LÉVI-STRAUSS, C. La pensée sauvage. Paris: Pocket-Plon, 2010.

LYONS, M. Livro: uma história viva. São Paulo: Editora Senac São Paulo, 2011.

McLUHAN, M. A galáxia de Gutenberg: a formação do homem tipográfico. São Paulo: Companhia Editora Nacional, 1977. 
MCLUHAN, M. Os meios de comunicação como extensões do homem. São Paulo: Cultrix, 2005.

McKENZIE, D. F. Making Meaning: "Printers of the Mind" and Other Essays. Edited by Peter D. McDonald \& Michael F. Suarez, S.J. Amherst, Boston: University of Massachusetts Press, 2002.

ONG, W. Oralidade e Cultura Escrita: a tecnologização da palavra. São Paulo: Papirus, 1998.

STENDHAL. O Vermelho e o Negro. Tradução de Paulo Neves. Porto Alegre: L\&PM, 2013.

VIVEIROS DE CASTRO, E. Metafísicas canibais: Elementos para uma antropologia pós-estrutural. São Paulo: Cosac Naify, 2015.

ZOLA, E. Germinal. São Paulo: Abril Cultural, 1979.

Artigo recebido em 15/02/2019 e aprovado em 23/04/2019. 